\title{
Enhanced Stability and Bioconjugation of Photo-cross-linked Polystyrene-Shell, Au-Core Nanoparticles
}

\author{
Ying Chen, Juhee Cho, Alexi Young, and T. Andrew Taton ${ }^{*}$ \\ Department of Chemistry, University of Minnesota 207 Pleasant St SE, Minneapolis, MN 55455
}

\section{Abstract}

Encapsulating Au nanoparticles within a shell of photo-cross-linked block copolymer surfactant dramatically improves the physical and chemical stability of the nanoparticles, particularly when they are applied as bioconjugates. Photo-cross-linkable block copolymer amphiphiles [polystyreneco-poly(4-vinyl benzophenone)]-block-poly(acrylic acid) [(PS-co-PVBP)- $b$-PAA] and [poly (styrene)-co-poly(4-vinyl benzophenone)]-block-poly(ethylene oxide) [(PS-co-PVBP)-b-PEO] were assembled around Au nanoparticles ranging from $12 \mathrm{~nm}$ to $108 \mathrm{~nm}$ in diameter. UV irradiation cross-linked the PVBP groups on the polymer to yield particles that withstood extremes of temperature, ionic strength, and chemical etching. Streptavidin was attached to [PS-co-PVBP]- $b-$ PAA coated particles using the same noncovalent and covalent conjugation protocols used to bind biomolecules to divinylbenzene-crosslinked polystyrene microspheres. We expect that these particles will be useful as plasmonic, highly light-scattering and light-absorbing analogs to fluorescently labeled polystyrene nanospheres.

\section{Introduction}

The plasmonic properties of metal nanoparticles ${ }^{1-3}$ _including large extinction and scattering cross-sections - make them attractive as alternatives to fluorescent tags in biological detection and imaging. ${ }^{4-8}$ For example, Au nanoparticles have been used as optical tags in a variety of detection schemes for DNA, ${ }^{9-11}$ proteins, ${ }^{12}, 13$ and other biomolecule analytes. Because it is straightforward to locate single metal nanoparticles by optical microscopy, ${ }^{14-18}$ metal nanoparticles have also been used in single-particle coding and tracking experiments in vitro, 19 in cells, ${ }^{20,21}$ and in vivo. ${ }^{22}$ In some respects, $\mathrm{Au}$ and $\mathrm{Ag}$ nanoparticles are plasmonic analogs of commercially available, fluorophore-doped polystyrene-co-divinylbenzene microand nanospheres that are widely used in biotechnology. However, bioconjugates of metal nanoparticles are often less stable to biological media or to the conditions of biotechnological protocols than bioconjugates of commercial nanospheres. Antibody and protein conjugates of Au nanoparticles are certainly stable as used in histochemical staining, ${ }^{23}$ and DNA-Au nanoparticle conjugates are compatible with hybridization buffers and room-temperature enzymatic manipulation. ${ }^{24-27} \mathrm{We}$ and others have shown, however, that the Au-thiol bonds commonly used to attach biomolecules to Au nanoparticle surfaces are unstable to high temperature, ${ }^{28}$ competing biological thiols, ${ }^{29,}, 30$ and chemical cleaving agents. 31,32 Researchers have worked to stabilize metal nanoparticle bioconjugates by linking biomolecules to particles with multiple thiols ${ }^{33-38}$ or other surface binders. ${ }^{39}$ Nevertheless,

\footnotetext{
*Author to whom correspondence should be addressed Email: taton@chem.umn.edu

Supporting Information Available. Details of the measurement of refractive index of PVBP, ${ }^{1} \mathrm{H}$ NMR characterization of polymers, UVVis spectra of Au nanoparticles, additional TEM images of nanoparticles, and further details on the determination of biotin binding sites on the surface of Au nanoparticles and thermal desorption assay. These materials are available free of charge via the Internet at http://pubs.acs.org.
} 
no surface chemistry so far has made Au nanoparticles as reliable to researchers in bioconjugate chemistry as commercial polystyrene beads.

In general, amphiphilic block copolymer surfactants can stabilize dispersions of hydrophobic nanoparticles in water without the need for covalent surface modification. $40-48$ We have recently reported that the stability of the surfactant layer can be further enhanced by chemically crosslinking the surfactant molecules. ${ }^{49-54}$ In those studies, we used polystyrene-block-poly (acrylic acid) (PS-b-PAA) and poly(methyl methacrylate)-block-poly(acrylic acid) (PMMA$b$-PAA) as encapsulating amphiphiles, and crosslinked the hydrophilic PAA block of the assembled polymer layer using aqueous carbodiimide/diamine coupling. 55 We have demonstrated this crosslinked-surfactant approach for various nanostructures, including

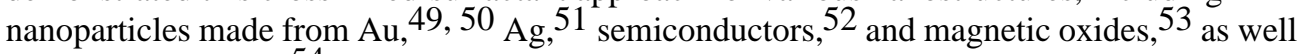
as carbon nanotubes. ${ }^{54}$ In all of these cases, the thick (10-20 nm), hydrophobic, glassy polymer layer surrounding each nanoparticle isolates it from the surrounding solvent environment ${ }^{56}$ and is readily engineered to provide chemical functionality for bioconjugation. ${ }^{57}$ However, these surfactants formed uniform, controlled layers only when the PAA block was much shorter than the hydrophobic block (to produce a "crew-cut" 58 layer), and as a result the density of cross-links in the assembled shell was low. Possibly as a result of this, while the stability of the particles was enhanced by PAA-cross-linked surfactants, the particles still did not survive the conditions of harsher biotechnological protocols (e.g., high-temperature methods involving thermophile enzymes).

By contrast, the stability and crosslink density of poly(styrene-co-divinylbenzene) micro- and nanospheres - the most commonly used particles for bioconjugate technology, and the model for the materials we have developed in this work-are comparably high. Cross-link density in these particles has been directly correlated with an increase in their glass transition temperature $\left(T_{\mathrm{g}}\right), 59,60$ a decrease in their permeability and tendency to swell in solvent, ${ }^{61,62}$ and a resulting increase in their physical integrity under conditions of high temperature and solvent swelling. Using crosslinked polystyrene microspheres as a model of stability, a goal of this study was to increase the crosslink density in asymmetric, PS-block surfactant shells by directly crosslinking the hydrophobic PS.

We report that nanoparticles can be further stabilized by encapsulating them with photochemically active, benzophenone-containing copolymer amphiphiles. In a previous paper, we described that photo-cross-linkable [polystyrene-co-poly(4-vinyl benzophenone)]block-poly(acrylic acid) [(PS-co-PVBP)- $b$-PAA] and [poly(styrene)-co-poly(4-vinyl benzophenone)]-block-poly(ethylene oxide) [(PS-co-PVBP)-b-PEO] could be synthesized from corresponding PS-containing diblock copolymers via mild Friedel-Crafts benzoylation with benzoyl triflate. ${ }^{63}$ Here we demonstrate that encapsulating Au nanoparticles within crosslinked shells of these amphiphiles dramatically improves the stability of the particles against heat, etchants, cosolvents, and buffers. Because incorporating PVBP into PS does not significantly change the physical properties of the polymer, we were able to use the same basic encapsulation strategy as we had for PS-block surfactants (Scheme 1). Amphiphiles and nanoparticles are first dissolved together in a solvent that is good for all components, and then water is gradually added to the mixture to assemble the hydrophobic block of the surfactant onto the hydrophobic nanaoparticles. UV irradiation of the benzophenone groups leads to photochemical crosslinking of the PS-co-PVBP cores and fixes the final nanostructure. In order to demonstrate the potential of these nanoparticles as substitutes for polystyrene nanospheres in bioconjugate applications, streptavidin was immobilized on the surface of (PS-co-PVBP)$b$-PAA encapsulated Au nanoparticles either by passive adsorption or by covalent attachment to the polymer. The stability of these bioconjugates makes them potential plasmonic replacements for crosslinked polystyrene nanospheres in biology. 


\section{Experimental Section}

\section{Materials}

All reagents used were purchased from Aldrich and used as received unless otherwise indicated. Styrene (99\%) and tert-butyl acrylate $(98 \%)$ were distilled over $\mathrm{CaH}_{2} \cdot \mathrm{PS}_{300}-b-\mathrm{PEO}_{385}\left(M_{\mathrm{w}} /\right.$ $M_{\mathrm{n}}=1.06$ ) was purchased from Polymer Source Inc. (Dorval, Canada). Biotin-fluorescein and photobiotin were purchased from Pierce Biotechnology Inc. (Rockford, IL).

\section{Characterization}

Transmission electron microscopy (TEM) images were obtained on a JEOL 1210 with a beam voltage of $120 \mathrm{kV}$. TEM samples were prepared by dropping suspensions directly onto TEM grids, without staining. UV-vis spectra were obtained on a Hewlett-Packard 8453 UV-vis spectrophotometer. Fluorescence spectra were collected with a PTI Quantamaster Fluorimeter (London, Ontario) at room temperature, using an excitation wavelength of $450 \mathrm{~nm}$ and $5 \mathrm{~nm}$ slit widths for both emission and excitation.

\section{Synthesis of Polymers}

Poly(styrene $)_{210}$-block-poly(tert-butyl acrylate $)_{22}\left(\mathrm{PS}_{210}-b-\mathrm{P} t \mathrm{BA}_{22} ; M_{\mathrm{n}}=25000 \mathrm{~g} / \mathrm{mol}, M_{\mathrm{w}} /\right.$ $M_{\mathrm{n}}=1.20$ ) was synthesized via sequential nitroxide-mediated radical polymerization (NMRP) of tert-butyl acylate and styrene. ${ }^{64}$ The benzoylated products of $\mathrm{PS}_{210^{-}} b-\mathrm{P} \mathrm{BA}_{22}$ and $\mathrm{PS}_{300^{-}}$ $b$ - $\mathrm{PEO}_{385}$ were prepared via Friedel-Crafts benzoylation as previously described. ${ }^{63,65}$

\section{Synthesis of Au Nanoparticles}

Au nanoparticles $(11.6 \pm 1.5 \mathrm{~nm}, 27.8 \pm 2.1 \mathrm{~nm}, 32.6 \pm 2.4 \mathrm{~nm}, 52.6 \pm 4.7 \mathrm{~nm}$ and $108.3 \pm 13.8$ $\mathrm{nm}$, determined by TEM) were synthesized by trisodium citrate reduction 66 or seeded growth. 65,67

\section{Encapsulation of Au Nanoparticles}

$\left(\mathrm{PS}_{0.65}-c o-\mathrm{PVBP}_{0.35}\right)_{210}-b-\mathrm{PAA}_{22}$ and $\left(\mathrm{PS}_{0.80}-c o-\mathrm{PVBP}_{0.20}\right)_{300}-b-\mathrm{PEO}_{385}$ were selected to encapsulate Au nanoparticles. Citrate-stabilized Au nanoparticles were first transferred into DMF by centrifugation and redispersion. As an example, $1 \mathrm{~mL}$ of citrate-stabilized $\mathrm{Au}$ nanoparticles $\left(d_{\mathrm{Au}}=32.6 \mathrm{~nm}, 0.48 \mathrm{nM}\right)$ was centrifuged at $16000 \times g$ for $10 \mathrm{~min}$. The upper layer $(\sim 980 \mu \mathrm{L})$ was carefully removed and discarded, and the same amount of DMF was added to the centrifugate. Next, $10 \mu \mathrm{L}$ of $\left(\mathrm{PS}_{0.65}-c o-\mathrm{PVBP}_{0.35}\right)_{210^{-}} b-\mathrm{PAA}_{22}$ solution $\left(10^{-2} \mathrm{~g} /\right.$ $\mathrm{mL}$ in DMF) was added. Then, $200 \mu \mathrm{L}$ of $\mathrm{H}_{2} \mathrm{O}$ was added gradually $(6.7 \mu \mathrm{L} / \mathrm{min})$ via syringe pump with continuous stirring, followed by $10 \mu \mathrm{L}$ of dodecanethiol solution ( $1 \mathrm{vol} \%$ in DMF). The resulting solution was stirred overnight. Subsequently, $3 \mathrm{~mL}$ of $\mathrm{H}_{2} \mathrm{O}$ was gradually added to the solution $(0.1 \mathrm{~mL} / \mathrm{min})$ with vigorous stirring. The solution was dialyzed (Spectra/Por ${ }^{\circledR}$ $4, \mathrm{MWCO}=12-14 \mathrm{~K}$ ) for at least $24 \mathrm{~h}$ against water to remove DMF. Encapsulated Au nanoparticle solutions were then irradiated in quartz test tubes using a UV Rayonet MiniReactor equipped with 8 RPR-3500 lamps (UVA 315-400 nm, Southern New England Ultra Violet Company, Branford, CT) and a circulating platform. Product nanoparticles were separated from empty micelles and unassembled polymers by centrifugation $(5200 \times g, 10$ $\mathrm{min})$, removal of the supernatant, and redispersion. Encapsulation with $\left(\mathrm{PS}_{0.80^{-}} \mathrm{Co}\right.$ $\left.\mathrm{PVBP}_{0.20}\right)_{300}-b-\mathrm{PEO}_{385}$ was performed similarly.

\section{Stability against Etching}

Aliquots of a $0.13 \mathrm{nM}$ suspension of Au nanoparticles $\left(1.5 \mathrm{~mL}\right.$ each; $\left.d_{\mathrm{Au}}=32.6 \mathrm{~nm}\right)$ encapsulated in $\left(\mathrm{PS}_{0.65}-c o-\mathrm{PVBP}_{0.35}\right)_{210}-b-\mathrm{PAA}_{22}\left(t_{\text {shell }}=11.9 \mathrm{~nm}\right)$ were irradiated for different times (from $0 \mathrm{~h}$ to $6 \mathrm{~h}$ ), and were then centrifuged and re-dispersed into the same

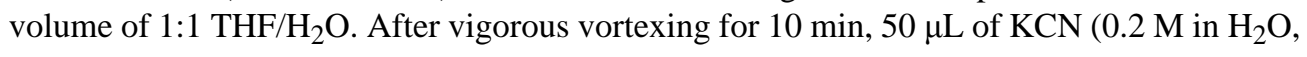


50 equiv to $\mathrm{Au}$ atoms) was added to the solution. UV-vis spectra of these suspensions were then collected over time.

\section{Stability in Buffer}

Citrate-stabilized Au nanoparticles $\left(d_{\mathrm{Au}}=32.6 \mathrm{~nm}, 0.07 \mathrm{nM}\right)$ and $\left(\mathrm{PS}_{0.65^{-}} \mathrm{co}-\mathrm{PVBP}_{0.35}\right)_{210^{-}}$ $b$-PAA 22 encapsulated Au nanoparticles $\left(d_{\mathrm{Au}}=32.6 \mathrm{~nm}, t_{\text {shell }}=11.9 \mathrm{~nm}, 0.05 \mathrm{nM}\right.$, UVirradiated $4 \mathrm{~h}$ ) were dialyzed against buffers, including Tris buffer $(10 \mathrm{mM}, \mathrm{pH} 7.0)$, carbonate buffer (25 mM, pH 10.5), MES buffer (50 mM, pH 6.10) and phosphate buffer ( $0.1 \mathrm{M}, \mathrm{pH} 7$ and 8), individually. The UV-vis spectra of these suspensions were measured after $24 \mathrm{~h}$ to evaluate stability.

\section{Modification of Encapsulated Au Nanoparticles with Photobiotin}

A $4 \mathrm{~mL}$ suspension of $\left(\mathrm{PS}_{0.65} \text {-co-PVBP } 0.35\right)_{210}-b$ - $\mathrm{PAA}_{22}$ encapsulated Au nanoparticles $\left(d_{\mathrm{Au}}=27.8 \mathrm{~nm}, t_{\text {shell }}=12.5 \mathrm{~nm}, 0.2 \mathrm{nM}\right.$, UV-irradiated $\left.4 \mathrm{~h}\right)$ was mixed with $4.2 \mu \mathrm{L}$ of an aqueous solution of photobiotin $(0.94 \mathrm{mM} ; 5000$ equivalents to Au nanoparticles) in the dark for $30 \mathrm{~min}$. The mixture was transferred into quartz test tubes and irradiated for another $30 \mathrm{~min}$ in a Rayonet Mini-Reactor equipped with eight RPR-3500 lamps (UVA 315 - $400 \mathrm{~nm}$, Southern New England Ultra Violet Co., Branford, CT) and a circulating platform. Excess photobiotin was removed by centrifugation $(5200 \times g, 10 \mathrm{~min})$, removal of the supernatant, and redispersion.

\section{Adsorption of Streptavidin on Encapsulated Au Nanoparticles}

An appropriate volume of dissolved streptavidin $(1 \mathrm{mg} / \mathrm{mL})$ was mixed with $4 \mathrm{~mL}$ of either unmodified or photobiotin-modified encapsulated Au nanoparticles $\left(d_{\mathrm{Au}}=27.8 \mathrm{~nm}, t_{\text {shell }}=\right.$ $12.5 \mathrm{~nm}, 0.2 \mathrm{nM}, \mathrm{UV}$-irradiated $4 \mathrm{~h}$ ), and the mixture was shaken for $2 \mathrm{~h}$ at room temperature. The suspension was then incubated at $4{ }^{\circ} \mathrm{C}$ overnight. Conjugates were isolated from unconjugated strepavidin by microfiltration (Millipore Amicon Ultra-4, $100 \mathrm{kDa}$ ).

\section{Thermal Desorption}

A suspension of encapsulated Au nanoparticles functionalized with streptavidin was heated under $70{ }^{\circ} \mathrm{C}$ water bath for $1 \mathrm{~h}$. The desorbed streptavidin was removed by microfiltration.

\section{Quantitative Analysis of Adsorbed Streptavidin by Cumulative Titration of Biotin-Fluorescein}

In a quartz cuvette at $25^{\circ} \mathrm{C}, 60 \mu \mathrm{L}$ aliquots of biotin-fluorescein $(0.8 \mu \mathrm{g} / \mathrm{mL})$ were successively added at 10 min intervals to a suspension of encapsulated Au nanoparticles functionalized with streptavidin $(0.8 \mathrm{~mL}, 0.065 \mathrm{nM})$. Fluorescence spectra were collected at each addition $\left(\lambda_{\mathrm{ex}}=\right.$ $\left.450 \mathrm{~nm}, \lambda_{\mathrm{em}}=505-535 \mathrm{~nm}\right)$.

\section{Results and Discussion}

\section{Photo-encapsulation of Au Nanoparticles}

In this work, as in our previous research on crosslinkable block-copolymer surfactants for nanoparticles, we used a two-step process to coat nanoparticles with cross-linkable blockcopolymer surfactants: we first assembled amphiphiles on the nanoparticles surface, and then we crosslinked the surfactants to fix the structure. Au nanoparticles and (PS-co-PVBP)-based block copolymers were first dispersed together in DMF. Then, water and a small amount of dodecanethiolwe re added simultaneously to drive assembly. As we found in our previous study on PS- $b$-PAA encapsulated $\mathrm{Au},{ }^{50}$ in order to assemble the block copolymer onto the particle surface, it was necessary to make the aqueous Au nanoparticles hydrophobic by including dodecanethiolin the water addition step. In the absence of dodecanethiol, no surfactant adsorption or encapsulation was observed, and adding thiol before the water and surfactant 
(rather than simultaneously) led to agglomeration of the unprotected, hydrophobic Au. Initial tests on $\left(\mathrm{PS}_{(1-x)^{-}} \text {co-PVBP }\right)_{210}-b$-PAA 22 copolymer surfactants, with PVBP fractions ranging from $x=0.10$ to 0.65 , showed that all of these polymers assembled around 32-nm diameter Au nanoparticles under similar conditions as the parent $\mathrm{PS}_{210}-b-\mathrm{PAA}_{22}$. This observation confirmed that PVBP is an excellent physical substitute for PS.

We focused on one of the copolymers, $\left(\mathrm{PS}_{0.65}-c o-\mathrm{PVBP}_{0.35}\right)_{210}-b-\mathrm{PAA}_{22}$, to study encapsulation of Au by photo-cross-linking. After assembly of this copolymer in $\mathrm{H}_{2} \mathrm{O}$, followed by extensive dialysis to remove residual DMF, the dialyzed solution was irradiated with UV light in a photoreactor (typically for $4 \mathrm{~h}$ ) to crosslink the benzophenone groups. $\mathrm{We}^{63}$ and others ${ }^{68-72}$ have previously characterized the chemistry of the benzophenone crosslinking reaction in polymeric and micellar systems by analytical spectroscopy. However, the large extinction and scattering coefficients of the encapsulated Au particles, and the small amount of polymer used to encapsulate each nanoparticle suspension, made it impractical to do the same chemical analysis on polymer crosslinked around Au nanoparticles. As a result, we analyzed the physical properties of the surfactant shells as an indicator of the success and impact of photo-cross-linking.

TEM images of $\mathrm{Au}$ nanoparticles encapsulated within $\left(\mathrm{PS}_{0.65}-c o-\mathrm{PVBP}_{0.35}\right) 210-b-\mathrm{PAA}_{22}$ shells showed well-dispersed, singly-encapsulated particles with polymer layers of consistent, uniform thickness (Figure 1). TEM images of the surfactant-coated particles before and after crosslinking showed that the size of the Au nanoparticle core and the thickness of the surfactant shell remained the same throughout UV irradiation. ${ }^{65}$ This confirms our hypothesis that the glassy hydrophobic block transiently freezes the assembled nanostructure, and that photocrosslinking does not alter that structure. Using $\left(\mathrm{PS}_{0.65}-c o-\mathrm{PVBP}_{0.35}\right)_{210}-b-\mathrm{PAA}_{22}$ as an encapsulating surfactant (for which we estimate a contour length $L=57 \mathrm{~nm}$ ), the thickness of the assembled polymer shell ranged from 7-30 $\mathrm{nm}$. Using the volumes of the PS and PVBP repeat units, we calculate that between $10^{3}$ and $10^{5}$ surfactant chains (for 7 and $30 \mathrm{~nm}$-thick shells, respectively) surround each particle. 65 Consistent with our previous studies on encapsulation by PS- $b$-PAA, ${ }^{49}$ and with theoretical work on the adsorption of polymeric surfactants on curved surfaces, ${ }^{73-76}$ shell thickness was dictated by the concentration of surfactant relative to the available surface area of nanoparticles. As a result, the thickness of the polymer shell surrounding each particle could be programmed according to the concentration of surfactant in the initial DMF solution. Different sized Au nanoparticles, ranging from $11.6 \mathrm{~nm}$ to $108.3 \mathrm{~nm}$ in diameter, were successfully encapsulated within crosslinked amphiphile shells by this strategy (Figure 2). Although the shells were generally uniform for all nanoparticle diameters, our larger particles were not as perfectly spherical as our smaller particles, and TEM images showed that the surfactant shells thinned at edges and corners on the surfaces of the larger particles (leading to greater shell polydispersity for larger particles). 65 This observation is consistent with our previous report on surfactant-coated nanoparticle morphologies, in which we determined that greater surface curvature led to thinner surfactant coatings. 49

During encapsulation, the color of the nanoparticle solution changes from red to purple as the surface plasmon absorbance of the particles is red-shifted (Figure 2I-L). This change is due to the response of the surface plasmon resonance to the refractive index $(n)$ of the particles' local environment. ${ }^{77}$ By encapsulation, the DMF $\left(n_{\mathrm{DMF}}=1.43\right)$ and water $\left(n_{\mathrm{H}_{2} \mathrm{O}}=1.33\right)$ surrounding each Au nanoparticle is displaced by a shell of PS-co-PVBP $\left(n_{\mathrm{PS}}=1.59 ; n_{\mathrm{PVBP}}\right.$ $=1.56^{65}$ ). The surface plasmon peak was not changed by surfactant cross-linking, indicating that the refractive index of the cross-linked PS-co-PVBP shell was nearly identical to that of uncrosslinked material. 
Because this approach involved cross-linking the hydrophobic copolymer block, we were able to apply it to (PS-co-PVBP)-based polymers containing other hydrophilic blocks. We used the same procedure to encapsulate $\mathrm{Au}$ nanoparticles within $\left(\mathrm{PS}_{0.80}-c o-\mathrm{PVBP}_{0.20}\right)_{300}-b-\mathrm{PEO}_{385}$ as we had with (PS-co-PVBP)- $b$-PAA. A representative TEM image of the resulting, encapsulated Au nanoparticles is shown in Figure 3. The shell thicknesses and optical properties of these particles were qualitatively similar to those of particles encapsulated with (PS-co-PVBP)- $b$ PAA.

\section{Effect of UV Cross-linking Time on Nanoparticle Stability against Etching}

We have previously established that surrounding Au nanoparticles with glassy, PS-block surfactants restricts the traffic of small molecules and ions between the nanoparticle surface and the surrounding aqueous environment. ${ }^{50,56} \mathrm{We}$ had also shown that adding a co-solvent that was good for the hydrophobic block (such as THF or DMF for PS) permeabilized the crosslinked layer without dissolving it away. In those experiments, although there was a clear difference between surfactant shells that were cross-linked and those that were not, the permeability and plasticity of the PS- $b$-PAAcoating did not decrease with increased crosslinking. This was presumably because it was the (minority) PAA block that was cross-linked. In this study, we hypothesized that photo-cross-linking the hydrophobic PS would inhibit permeation of the majority block by co-solvent and other species.

TEM images of nanoparticles that were encapsulated in $\left(\mathrm{PS}_{0.65}-c o-\mathrm{PVBP}_{0.35}\right)_{210}-b-\mathrm{PAA}_{22}$ either with or without cross-linking, and that were subsequently exposed to DMF co-solvent, showed that crosslinking did indeed reduce shell permeability. Uncross-linked shells were easily deformed or dissolved away by added DMF, while nanoparticles exposed to $4 \mathrm{~h}$ of UV irradiation looked identical by TEM to those that were imaged from water. ${ }^{65}$ To get a more quantitative measure of shell permeability, we investigated the susceptibility of the encapsulated Au metal to oxidative etching 78 by dissolved KCN. In aqueous solution, both cross-linked and uncross-linked encapsulated Au nanoparticles, were stable for months in the presence of a considerable molar excess of cyanide ions. By contrast, surface-bound molecular, 79 multiple-layered polyelectrolyte ${ }^{80}$ and silica shells 81 have been shown to be permeable with respect of cyanide corrosion. The permeability of micelle to $\mathrm{CN}^{-}$was further tested by adding an organic co-solvent to the aqueous nanoparticle suspension in order to swell the hydrophobic polymer block. Nanoparticles were transferred into $1: 1(v / v) \mathrm{THF} / \mathrm{H}_{2} \mathrm{O}$, and again exposed to excess KCN. Surfactant-coated Au nanoparticles that had not been cross-linked by UV irradiation quickly reacted with the $\mathrm{CN}^{-}$, as indicated by the decrease in the particles' characteristic surface plasmon absorbance (Figure 4). However, when the particles were first irradiated to cross-link the surfactant, the subsequent stability of the particles against THF/ $\mathrm{CN}^{-}$infiltration was increased. Resistance against $\mathrm{CN}^{-}$etching progressively increased with longer UV irradiation times, up to about $2 \mathrm{~h}$; with $\mathrm{UV}$ irradiation beyond this time, the particles were indefinitely stable to added $\mathrm{CN}^{-}$in $1: 1 \mathrm{THF} / \mathrm{H}_{2} \mathrm{O}$. This is consistent with our characterization of crosslinking in empty (PS-co-PVBP)- $b$-PAA micelles, which showed that $\mathrm{UV}$ crosslinking required hours of UV exposure under the same conditions used here. ${ }^{63}$

When highly cross-linked (UV exposure $\geq 2 \mathrm{~h}$ ) encapsulated Au nanoparticles were redispersed into pure THF and treated with excess KCN (e.g. 1000 equiv per Au atom), the encapsulated Au was completely etched. We found it was possible to recover the resulting hollowed polymer shells and image them by TEM (Figure 5). Interestingly, these highly crosslinked capsules did not collapse, but instead show hollow centers with diameters close to those of the original Au nanoparticles. 


\section{Assay of Stability in Organic and Buffer Media}

We found that (PS-co-PVBP)- $b$-PAA-encapsulated nanoparticles improved the suspension of large $(d>20 \mathrm{~nm})$ Au nanoparticles in a variety of environments, including organic solvents and buffers. Ordinarily, large, citrate-capped Au nanoparticles flocculate from aqueous suspension in the presence of even small amounts of added organic co-solvents or salts, and this is reflected by a decrease in the solution extinction of the suspension (Figure 6A). We found that nanoparticles coated with cross-linked (PS-co-PVBP)- $b$-PAA, on the other hand, could be transferred to organic solvents or buffers without precipitation (Figure 6B). In this respect, the integrity of the particles under different solvent conditions was qualitatively similar to that of crosslinked poly(styrene-co-divinylbenzene) microspheres, which are frequently used as solid supports in all of these media.

\section{Conjugation with Streptavidin}

A variety of methods have been used to immobilize biomolecules on the surfaces of polystyrene particles, including passive adsorption, 82,83 chemical attachment to functional groups on the particle surface, ${ }^{84}$ and affinity attachment to pre-coated surfaces with generic binding proteins. 85 We initially evaluated passive (non-specific) adsorption of streptavidin to (PS-co-PVBP)$b$-PAA encapsulated Au nanoparticles, by incubating the particles with streptavidin under conditions normally used to conjugated polystyrene microspheres. We quantified the nanoparticle-bound streptavidin with a fluorometric titration method in which biotin-binding sites partially quench the fluorescence of added biotin-fluorescein until all the binding sites are occupied. ${ }^{86,87}$ In graphs of fluorescence intensity versus added biotin-fluorescein (Figure $7 \mathrm{~A}$ ), a kink indicates this saturation point, ${ }^{65}$ and corresponds to the number of particle-bound biotin-binding sites. We found the number of biotin-binding sites per particle correlated reproducibly with the amount of streptavidin used in the conjugation protocol, up to a maximum of 240 biotin-binding sites per nanoparticle (Figure 7B). If each surface-bound streptavidin had only two out of four biotin binding sites available (as is often observed for surface-adsorbed biotin), ${ }^{88}$ then we estimate 120 streptavidin molecules per particle. Given a surface area of $8800 \mathrm{~nm}^{2}$ for each $52.8-\mathrm{nm}$ diameter nanoparticle $\left(d_{\mathrm{Au}}=27.8 \mathrm{~nm}, t_{\text {shell }}=12.5 \mathrm{~nm}\right)$, and a footprint of $34 \mathrm{~nm}^{2}$ for streptavidin, ${ }^{89}$ about half of the surface area of each particle is covered with streptavidin. Although passive adsorption of streptavidin onto (PS-co-PVBP)- $b$-PAA coated Au was very efficient, we observed $\sim 10$ times less adsorption onto (PS-co-PVBP)- $b$ PEO-coated Au, ${ }^{65}$ consistent with the more adsorption-resistant characteristics of the PEO shell. ${ }^{90}$

We also investigated specific attachment of streptavidin to the nanoparticle surfaces. We initially expected that photo-cross-linking (PS-co-PVBP)- $b$-PAA coated Au would leave the hydrophilic PAA layer available for covalent chemistry. However, attempts to conjugate streptavidin or fluorescent small-molecule amines to PAA carboxylates using standard carbodiimide coupling protocols failed. Instead, we first modified the particles with photobiotin 91 under further irradiation with UV light, and then attached streptavidin to the surface-bound biotin. When biotinylated particles were combined with large (saturating) amounts of streptavidin, the maximum number of biotin-binding sites assayed on these particles was $\sim 290$ per particle, very similar to the value determined for passively functionalized particles. In cases where biotinylated particles were combined with substoichiometric amounts of streptavidin, the particles formed streptavidin-linked aggregates as has been previously observed for other biotinylated particles. 35

The stabilities of passively and specifically linked streptavidin-nanoparticles conjugates were quite different. After being heated at $70{ }^{\circ} \mathrm{C}$ for $1 \mathrm{~h}$, passively adsorbed streptavidin was completely dissociated from the surface of the encapsulated Au nanoparticles, as indicated by a failure to titrate any biotin binding sites in these samples. For streptavidin that was bound to 
the photobiotin-modified Au nanoparticles, on the other hand, $70 \%$ of the biotin binding sites remained after exposure to $70{ }^{\circ} \mathrm{C}$ for $1 \mathrm{~h} .65 \mathrm{We}$ argue that the other $30 \%$ of streptavidin may have been bound nonspecifically to the photobiotin-functionalized particles and then desorbed upon heating; isolation of heated particles from suspension, followed by re-exposure to another round of heating at $70{ }^{\circ} \mathrm{C}$ for $1 \mathrm{~h}$, showed no further loss of streptavidin. We also found that, after conjugation with streptavidin, the photobiotin-modified particles were more stable to long-term storage in water and buffers than the passively adsorbed particles, possibly due to gradual desorption of passively adsorbed streptavidin at room temperature. This suggests that photobiotinylated, (PS-co-PVBP)- $b$-PAA encapsulated Au nanoparticles might show potential as nanoscale, plasmonic variants of the larger polystyrene microspheres commonly used in protocols for genomics and proteomics.

\section{Conclusions}

We have developed a method for encapsulating Au nanoparticles within shells of photo-crosslinked, benzophenone -containing block copolymer amphiphile. These cross-linked polymer shells provide a protective layer against chemicaletching and improve the stability of nanoparticles in both organic solvents and biochemical buffers. We were also able to functionalize the surfaces of these particles with streptavidin, either by passive adsorption or by conjugation to surface-bound biotin groups.

\section{Supplementary Material}

Refer to Web version on PubMed Central for supplementary material.

\section{Acknowledgement}

This work was supported by the National Institutes of Health (1 R21 EB003809-01). We thank Prof. Mark Distefano for use of the Rayonet photoreactor and Prof. Andreas Stein for use of the Abbé refractometer.

\section{References}

1. Rotello, V. Nanoparticles: Building Blocks for Nanotechnology. Kluwer Academic; New York: 2004.

2. Rao, CNR.; Muller, A.; Cheetham, AK. The Chemistry of Nanomaterials: Synthesis, Properties and Applications. Wiley-VCH; Weinheim: 2004.

3. Feldheim, DL.; Foss, CL. Metal Nanoparticles: Synthesis, Characterization, and Applications. Marcel Dekker; New York: 2002.

4. Rosi NL, Mirkin CA. Chem. Rev 2005;105:1547-1562. [PubMed: 15826019]

5. Aslan K, Lakowicz JR, Geddes CD. Curr. Opin. Chem. Biol 2005;9:538-544. [PubMed: 16129649]

6. Haes AJ, Stuart DA, Nie SM, Van Duyne RP. J. Fluoresc 2004;14:355-367. [PubMed: 15617378]

7. Katz E, Willner I. Angew. Chem., Int. Ed 2004;43:6042-6108.

8. Niemeyer CM. Angew. Chem., Int. Ed 2001;40:4128-4158.

9. Thaxton CS, Georganopoulou DG, Mirkin CA. Clin. Chim. Acta 2006;363:120-126. [PubMed: 16214124]

10. Fritzsche W, Taton TA. Nanotechnology 2003;14:R63-R73.

11. Foultier B, Moreno-Hagelsieb L, Flandre D, Remacle J. IEE Proc.-Nanobiotechnol 2005;152:3-12. [PubMed: 16441154]

12. Nath N, Chilkoti A. J. Fluoresc 2004;14:377-389. [PubMed: 15617380]

13. Nam JM, Thaxton CS, Mirkin CA. Science 2003;301:1884-1886. [PubMed: 14512622]

14. van Dijk MA, Tchebotareva AL, Orrit M, Lippitz M, Berciaud S, Lasne D, Cognet L, Lounis B. Phys. Chem. Chem. Phys 2006;8:3486-3495. [PubMed: 16871337]

15. Sonnichsen C, Alivisatos AP. Nano Lett 2005;5:301-4. [PubMed: 15794615]

16. van Dijk MA, Lippitz M, Orrit M. Acc. Chem. Res 2005;38:594-601. [PubMed: 16028894] 
17. Mock JJ, Smith DR, Schultz S. Nano Lett 2003;3:485-491.

18. Yguerabide J, Yguerabide EE. Anal. Biochem 1998;262:157-176. [PubMed: 9750129]

19. Sonnichsen C, Reinhard BM, Liphard J, Alivisatos AP. Nat. Biotechnol 2005;23:741-745. [PubMed: 15908940]

20. Cognet L, Tardin C, Boyer D, Choquet D, Tamarat P, Lounis B. Proc. Natl. Acad. Sci. U. S. A 2003;100:11350-11355. [PubMed: 13679586]

21. Schultz S, Smith DR, Mock JJ, Schultz DA. Proc. Natl. Acad. Sci. U. S. A 2000;97:996-1001. [PubMed: 10655473]

22. Paciotti G, Myer L, Weinreich D, Goia D, Pavel N, McLaughlin R, Tamarkin L. Drug Delivery 2004;11:169-183. [PubMed: 15204636]

23. Hayat, MA. Colloidal Gold: Principles, Methods and Applications. Academic Press; New York: 1989.

24. Liu GL, Yin Y, Kunchakarra S, Mukherjee B, Gerion D, Jett SD, Bear DG, Gray JW, Alivisatos AP, Lee LP, Chen FF. Nat. Nanotechnol 2006;1:47-52. [PubMed: 18654141]

25. Kanaras AG, Wang Z, Bates AD, Cosstick R, Brust M. Angew. Chem., Int. Ed 2003;42:191-194.

26. Tsai C-Y, Shiau A-L, Cheng P-C, Shieh D-B, Chen D-H, Chou C-H, Yeh C-S, Wu C-L. Nano Lett 2004;4:1209-1212.

27. Nicewarner-Peña SR, Raina S, Goodrich GP, Fedoroff NV, Keating CD. J. Am. Chem. Soc 2002;124:7314-7323. [PubMed: 12071740]

28. Herdt AR, Drawz SE, Kang Y, Taton TA. Colloids Surf., B 2006;51:130-139.

29. Hong R, Han G, Fernandez JM, Kim BJ, Forbes NS, Rotello VM. J. Am. Chem. Soc 2006;128:10781079. [PubMed: 16433515]

30. Hostetler MJ, Templeton AC, Murray RW. Langmuir 1999;15:3782-3789.

31. Han G, Martin CT, Rotello VM. Chem. Biol. Drug Des 2006;67:78-82. [PubMed: 16492152]

32. Mittal S, Bushman F, Orgel LE. J. Chem. Technol. Biotechnol 2003;78:471-473.

33. Li Z, Jin R, Mirkin CA, Letsinger RL. Nucleic Acids Res 2002;30:1558-1562. [PubMed: 11917016]

34. Storhoff JJ, Elghanian R, Mirkin CA, Letsinger RL. Langmuir 2002;18:6666-6670.

35. Niemeyer CM, Burger W, Peplies J. Angew. Chem., Int. Ed 1998;37:2265-2268.

36. Siiman O, Burshteyn A, Maples JA, Whitesell JK. Bioconjugate Chem 2000;11:549-556.

37. Roux S, Garcia B, Bridot JL, Salome M, Marquette C, Lemelle L, Gillet P, Blum L, Perriat P, Tillement O. Langmuir 2005;21:2526-2536. [PubMed: 15752049]

38. Liu J, Ong W, Roman E, Lynn MJ, Kaifer AE. Langmuir 2000;16:3000-3002.

39. Schroedter A, Weller H. Angew. Chem., Int. Ed 2002;41:3218-3221.

40. Lefebvre MD, Shull KR. Macromolecules 2006;39:3450-3457.

41. Duxin N, Liu F, Vali H, Eisenberg A. J. Am. Chem. Soc 2005;127:10063-10069. [PubMed: 16011370]

42. Chen S, Guo C, Hu GH, Wang J, Ma JH, Liang XF, Zheng L, Liu HZ. Langmuir 2006;22:9704-9711. [PubMed: 17073500]

43. Frankamp BL, Uzun O, Ilhan F, Boal AK, Rotello VM. J. Am. Chem. Soc 2002;124:892-893. [PubMed: 11829582]

44. Loginova TP, Kabachii YA, Sidorov SN, Zhirov DN, Valetsky PM, Ezernitskaya MG, Dybrovina LV, Bragina TP, Lependina OL, Stein B, Bronstein LM. Chem. Mater 2004;16:2369-2378.

45. Moffitt M, Vali H, Eisenberg A. Chem. Mater 1998;10:1021-1028.

46. Wang CW, Moffitt MG. Langmuir 2005;21:2465-2473. [PubMed: 15752041]

47. Chen S, Zhu J, Shen Y, Hu C, Chen L. Langmuir 2007;23:850-854. [PubMed: 17209643]

48. Bronstein L, Chernyshov D, Valetsky P, Tkachenko N, Lemmetyinen H, Hartmann J, Foerster S.

Langmuir 1999;15:83-91.

49. Kang Y, Taton TA. Macromolecules 2005;38:6115-6121.

50. Kang Y, Taton TA. Angew. Chem., Int. Ed 2005;44:409-412.

51. Zuo, C.; Chen, Y.; Taton, TA. 2007. in preparation

52. Shibasaki, Y.; Kim, B-S.; Young, AJ.; McCloon, A.; Ekker, SC.; Taton, TA. 2006. submitted

53. Kim B-S, Qiu J-M, Wang J-P, Taton TA. Nano Lett 2005;5:1987-1991. [PubMed: 16218723] 
54. Kang Y, Taton TA. J. Am. Chem. Soc 2003;125:5650-5651. [PubMed: 12733901]

55. Huang HY, Remsen EE, Kowalewski T, Wooley KL. J. Am. Chem. Soc 1999;121:3805-3806.

56. Ge Z, Kang Y, Taton TA, Braun PV, Cahill DG. Nano Lett 2005;5:531-535. [PubMed: 15755109]

57. Herdt AR, Kim BS, Taton TA. Bioconjugate Chem 2007;18:183.

58. Zhang L, Eisenberg A. Science 1995;268:1728-1731. [PubMed: 17834990]

59. Ding Z-Y, Ma S, Kriz D, Aklonis JJ, Salovey R. J. Polym. Sci., Part B: Polym. Phys 1992;30:1189_ 1194.

60. Zou D, Derlich V, Gandhi K, Park M, Sun L, Kriz D, Lee YD, Kim G, Aklonis JJ, Salovey R. J.

Polym. Sci., Part A: Polym. Chem 1990;28:1909-1921.

61. Wiley RH. Pure Appl. Chem 1975;43:57-75.

62. Ding ZY, Aklonis JJ, Salovey R. J. Polym. Sci., Part B: Polym. Phys 1991;29:1035-1038.

63. Chen Y, Tavakley AE, Mathiason TM, Taton TA. J. Polym. Sci., Part A: Polym. Chem 2006;44:26042614.

64. Benoit D, Chaplinski V, Braslau R, Hawker CJ. J. Am. Chem. Soc 1999;121:3904-3920.

65. See Supporting Information for details.

66. Frens G. Nat. Phys. Sci 1973;241:20-22.

67. Brown KR, Walter DG, Natan MJ. Chem. Mater 2000;12:306-313.

68. Matsukuma D, Yamamoto K, Aoyagi T. Langmuir 2006;22:5911-5915. [PubMed: 16768529]

69. Chaney EE, Forbes MDE. J. Phys. Chem. B 2003;107:4464-4469.

70. Taton KS, Guire PE. Colloids Surf., B 2002;24:123-132.

71. Prucker O, Naumann CA, Ruehe J, Knoll W, Frank CW. J. Am. Chem. Soc 1999;121:8766-8770.

72. Braun AM, Krieg M, Turro NJ, Aikawa M, Gould IR, Graf GA, Lee PCC. J. Am. Chem. Soc 1981;103:7312-7316.

73. Singh N, Karim A, Bates FS, Tirrell M, Furusawa K. Macromolecules 1994;27:2586-94.

74. Hariharan R, Biver C, Mays J, Russel WB. Macromolecules 1998;31:7506-7513.

75. Biver C, Hariharan R, Mays J, Russel WB. Macromolecules 1997;30:1787-1792.

76. Qiu X, Wang Z-G. J. Colloid Interface Sci 1994;167:294-300.

77. Templeton AC, Pietron JJ, Murray RW, Mulvaney P. J. Phys. Chem. B 2000;104:564-570.

78. Zhu T, Vasilev K, Kreiter M, Mittler S, Knoll W. Langmuir 2003;19:9518-9525.

79. Isaacs SR, Cutler EC, Park J-S, Lee TR, Shon Y-S. Langmuir 2005;21:5689-5692. [PubMed: 15952810]

80. Schneider G, Decher G. Nano Lett 2004;4:1833-1839.

81. Poovarodom S, Bass JD, Hwang S-J, Katz A. Langmuir 2005;21:12348-12356. [PubMed: 16343013]

82. Liu B, Cao S, Deng X, Li S, Luo R. Appl. Surf. Sci 2006;252:7830-7836.

83. Lvov, Y.; Möhwald, H. Protein architecture: interfacing molecular assemblies and immobilization biotechnology. Marcel Dekker; New York: 2000.

84. Abad JM, Mertens SFL, Pita M, Fernandez VM, Schiffrin DJ. J. Am. Chem. Soc 2005;127:56895694. [PubMed: 15826209]

85. Buranda T, Jones GM, Nolan JP, Keij J, Lopez GP, Sklar LA. J. Phys. Chem. B 1999;103:3399_ 3410.

86. Gruber HJ, Kada G, Marek M, Kaiser K. Biochim. Biophys. Acta 1998;1381:203-212. [PubMed: 9685643]

87. Kada G, Falk H, Gruber HJ. Biochim. Biophys. Acta 1999;1427:33-43. [PubMed: 10082985]

88. Borcherding H, Hicke H-G, Jorcke D, Ulbricht M. Ann. N. Y. Acad. Sci 2003;984:470-479. [PubMed: 12783838]

89. Weber PC, Ohlendorf DH, Wendoloski JJ, Salemme FR. Science 1989;243:85-8. [PubMed: 2911722]

90. Harris, JM.; Zalipsky, S. Poly(ethylene glycol): chemistry and biological applications. American Chemical Society; Washington, DC: 1997.

91. Forster AC, McLnnes JL, Skingle DC, Symons RH. Nucl. Acids Res 1985;13:745-761. [PubMed: 2582358] 


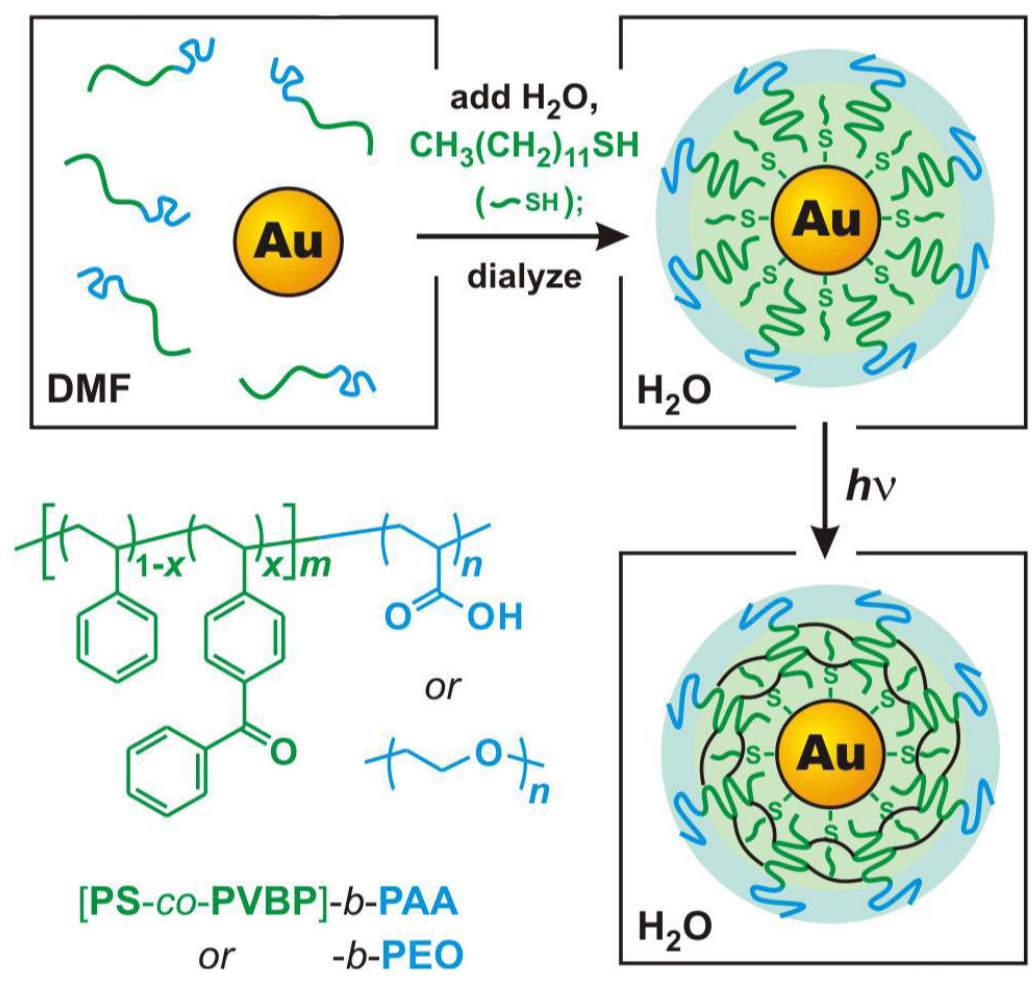

Scheme 1.

Encapsulation strategy. 

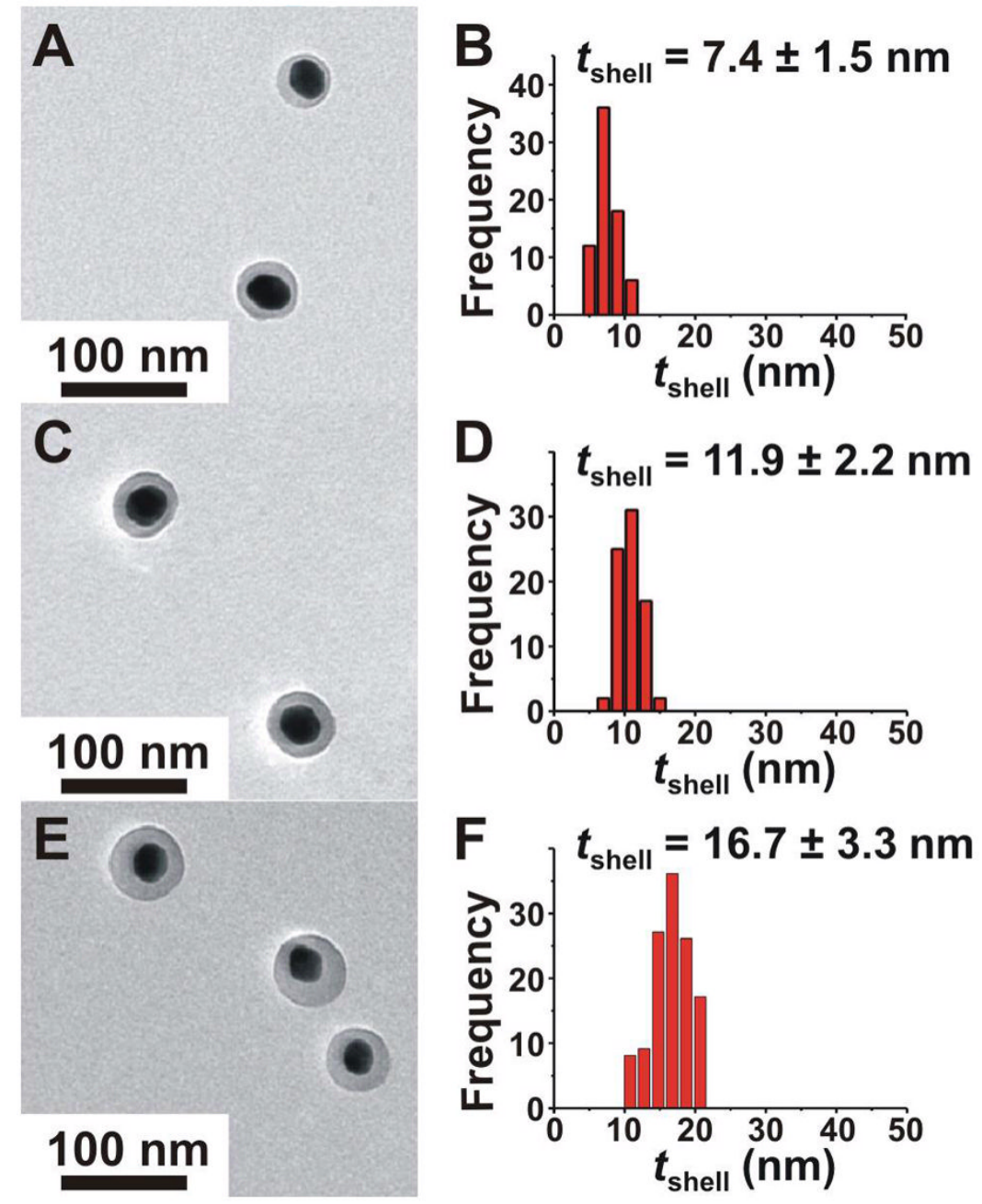

Figure 1.

TEM images (A,C,E) and histograms of shell thickness (B,D,F) for $32.6 \mathrm{~nm}$ Au nanoparticles encapsulated with different concentrations of block-copolymer surfactant: $\left[\left(\mathrm{PS}_{0.65}-\mathrm{CO}-\right.\right.$

$\left.\left.\mathrm{PVBP}_{0.35}\right)_{210}-b-\mathrm{PAA}_{22}\right] /\left(n_{m}^{s} A_{\text {Au }}^{\text {total }}\right)=(\mathrm{A}, \mathrm{B}) 2.5,(\mathrm{C}, \mathrm{D}) 5$ and $(\mathrm{E}, \mathrm{F}) 10$. The value $\left(n_{m}^{s} A_{\text {Au }}^{\text {total }}\right)$ is defined as the amount of polymer surfactant required to coat all nanoparticles in solution with a monolayer of thickness equal to the end-to-end distance $\left\langle h^{2}\right\rangle_{0}^{1 / 2}$ of one polymer chain. ${ }^{49}$ For $\left(\mathrm{PS}_{0.65}-c o-\mathrm{PVBP}_{0.35}\right)_{210}-b-\mathrm{PAA}_{22},\left(n_{m}^{s} A_{\mathrm{Au}}^{\text {total }}\right)=6.2 \times 10^{-7} \mathrm{M}$. Each of the histograms in (D-F) was constructed from multiple TEM images of the same sample. Particle multimers are apparent in some of these images; we attribute this to an artifact of drying during TEM sample preparation rather than particle agglomeration, based on our previous observations on similar nanoparticles 50 and on our observation that the fraction of observed multimers depends on the density of particles on the TEM grid (data not shown). 

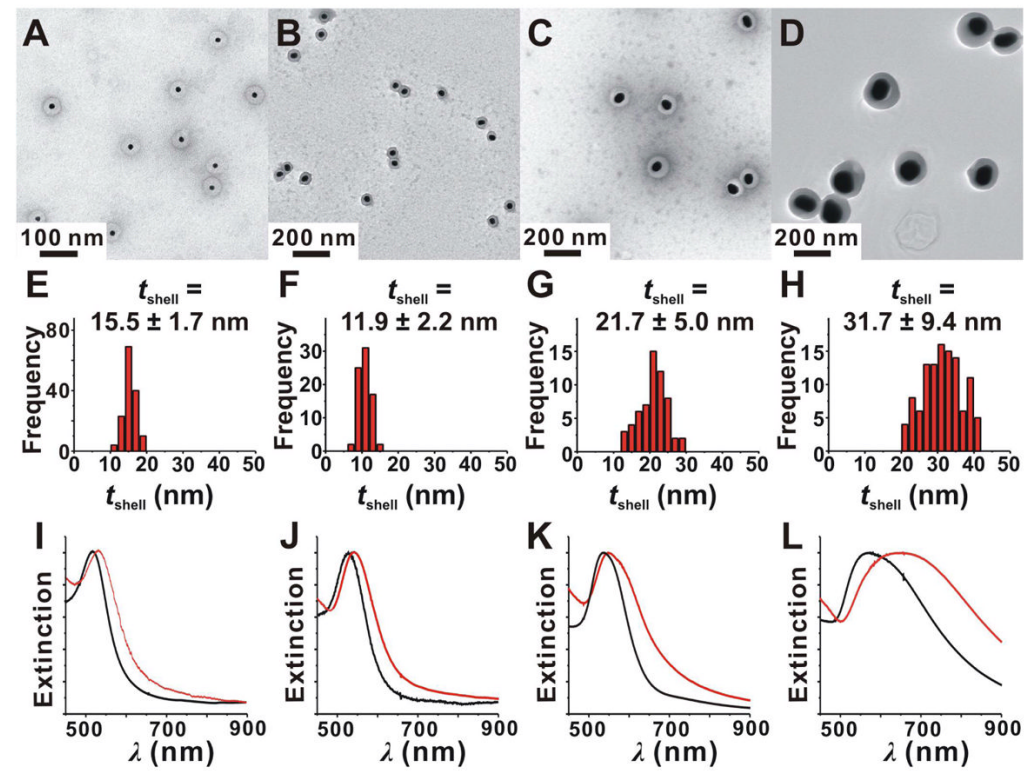

Figure 2.

(A-H) TEM images (A-D) and histograms of shell thickness (E-H) for encapsulated Au nanoparticles with core diameters $d_{\mathrm{Au}}=(\mathrm{A}, \mathrm{E}) 11.6 \mathrm{~nm},(\mathrm{~B}, \mathrm{~F}) 32.6 \mathrm{~nm},(\mathrm{C}, \mathrm{G}) 52.6 \mathrm{~nm}$ and $(\mathrm{D}, \mathrm{H}) 108.3 \mathrm{~nm}$. Each of the histograms in $(\mathrm{E}-\mathrm{H})$ was constructed from multiple TEM images of the same sample. In the synthesis of these materials, $\left[\left(\mathrm{PS}_{0.65}-\mathrm{co}-\mathrm{PVBP}_{0.35}\right)_{210}-b-\mathrm{PAA}_{22}\right] /$ $\left(n_{m}^{s} A_{\mathrm{Au}}^{\text {total }}\right)=5$. (I-L) UV-vis extinction spectra of aqueous Au nanoparticles in (A-D), before (black) and after (red) encapsulation with $\left(\mathrm{PS}_{0.65} \text {-co-PVBP } 0.35\right)_{210}-b$-PAA 22 . Extinction intensities are normalized. 

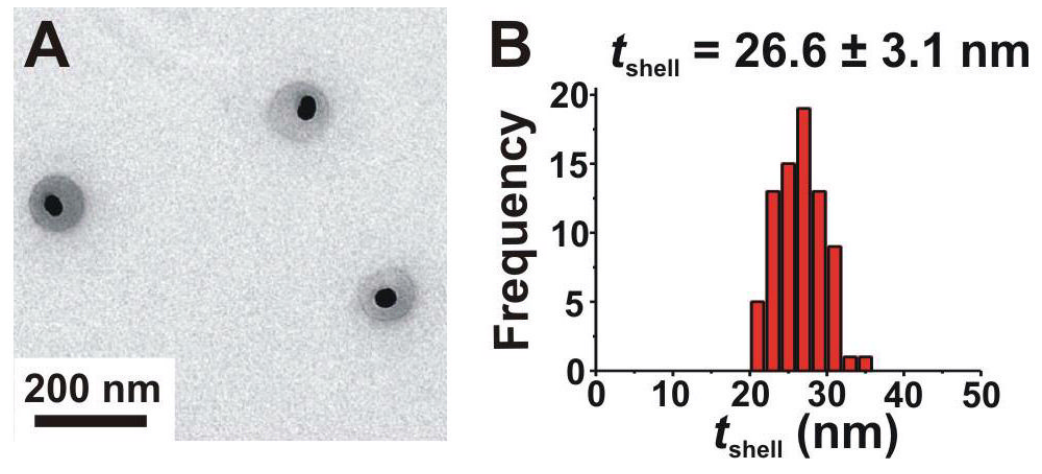

Figure 3.

TEM image (A) and histograms of shell thickness $(\mathrm{B})$ for $\left(\mathrm{PS}_{0.80}-c o-\mathrm{PVBP}_{0.20}\right)_{300}-b$ $\mathrm{PEO}_{385}$ encapsulated Au nanoparticles $\left(d_{\mathrm{Au}}=32.6 \mathrm{~nm}\right)$, with $\left[\left(\mathrm{PS}_{0.80}-c o-\mathrm{PVBP}_{0.20}\right)_{300^{-}} b\right.$ $\left.\mathrm{PEO}_{385}\right] /\left(n_{m}^{s} A_{\mathrm{Au}}^{\text {total }}\right)=5$. The histogram in (B) was constructed from multiple TEM images of the same sample. 


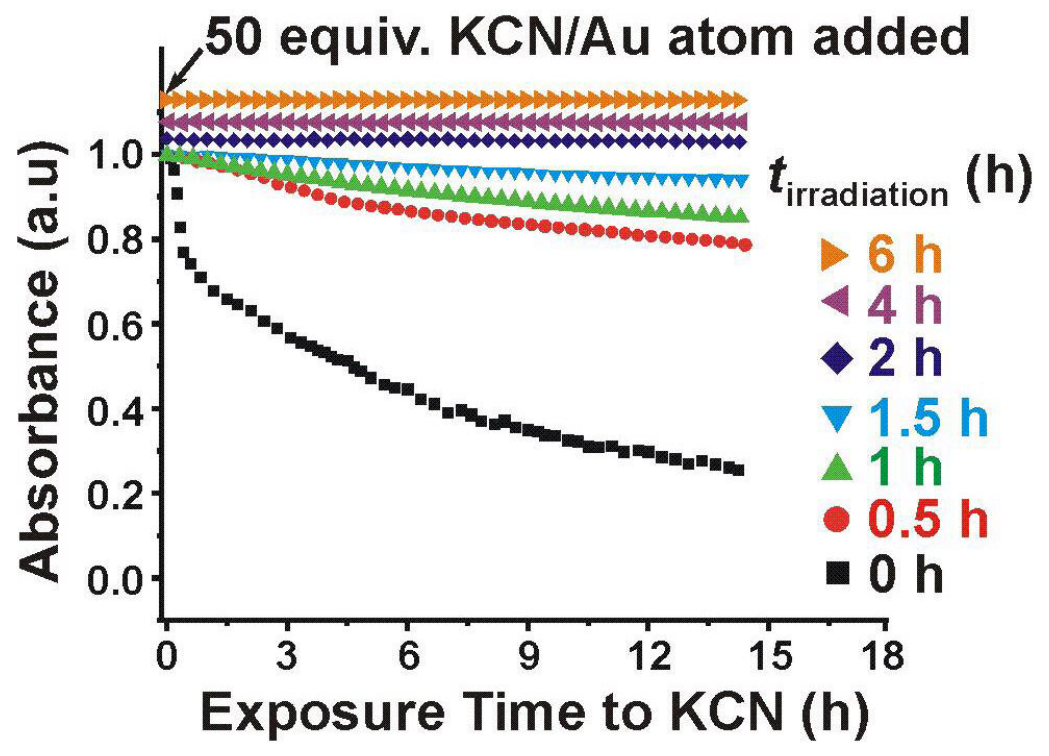

Figure 4.

Relative absorbance at $539 \mathrm{~nm}$ for encapsulated Au nanoparticles with different UV irradiation times in 1:1 THF/ $\mathrm{H}_{2} \mathrm{O}$ upon the addition of 50 equiv $\mathrm{KCN}$. 


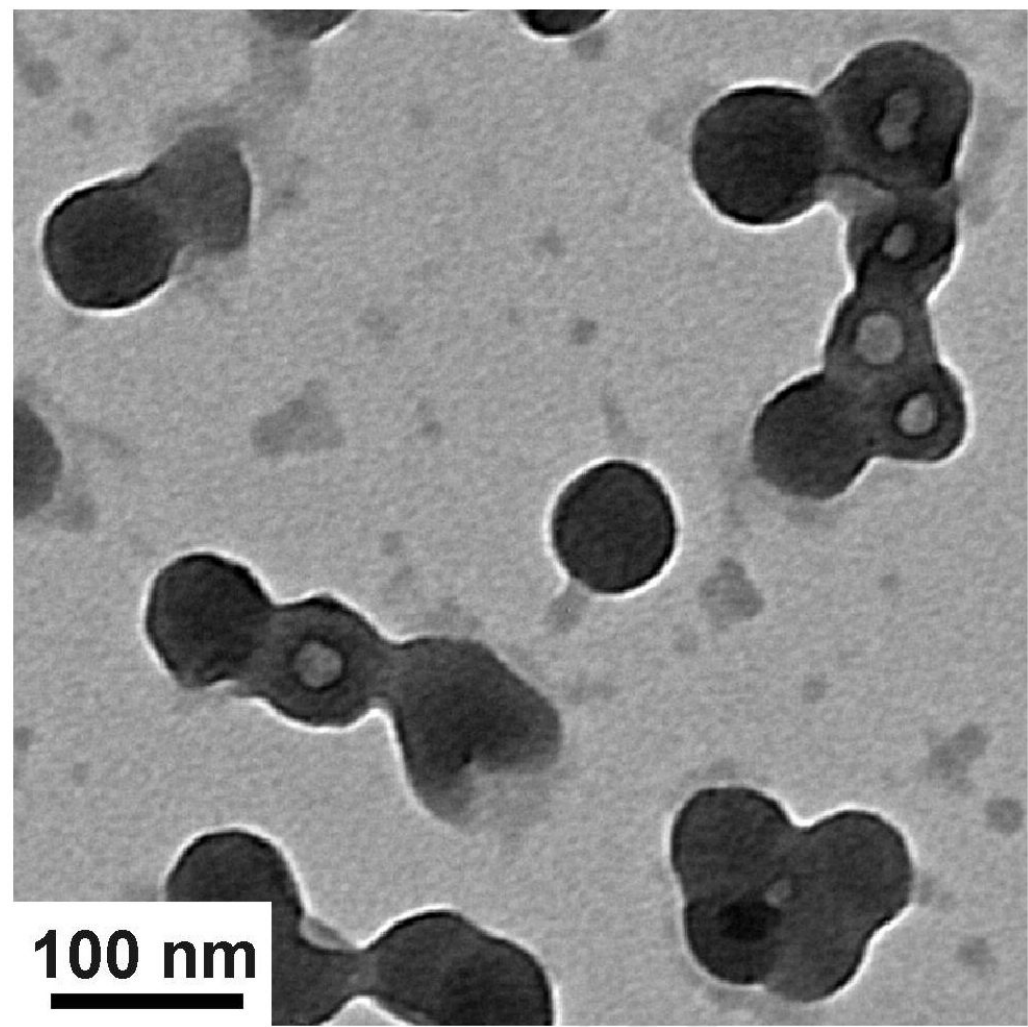

Figure 5.

TEM image of nanocapsules of $\left(\mathrm{PS}_{0.65} \text {-co-PVBP }{ }_{0.35}\right)_{210}-b-\mathrm{PAA}_{22}$ encapsulated $\mathrm{Au}$ nanoparticles $\left(d_{\mathrm{Au}}=32.6 \mathrm{~nm},\left[\left(\mathrm{PS}_{0.65} \text {-co-PVBP }{ }_{0.35}\right)_{210}-b-\mathrm{PAA}_{22}\right] /\left(n_{m}^{s} A_{\mathrm{Au}}^{\text {total }}\right)=5\right.$, UVirradiated $4 \mathrm{~h}$ ) after treatment with excess $\mathrm{KCN}$. 

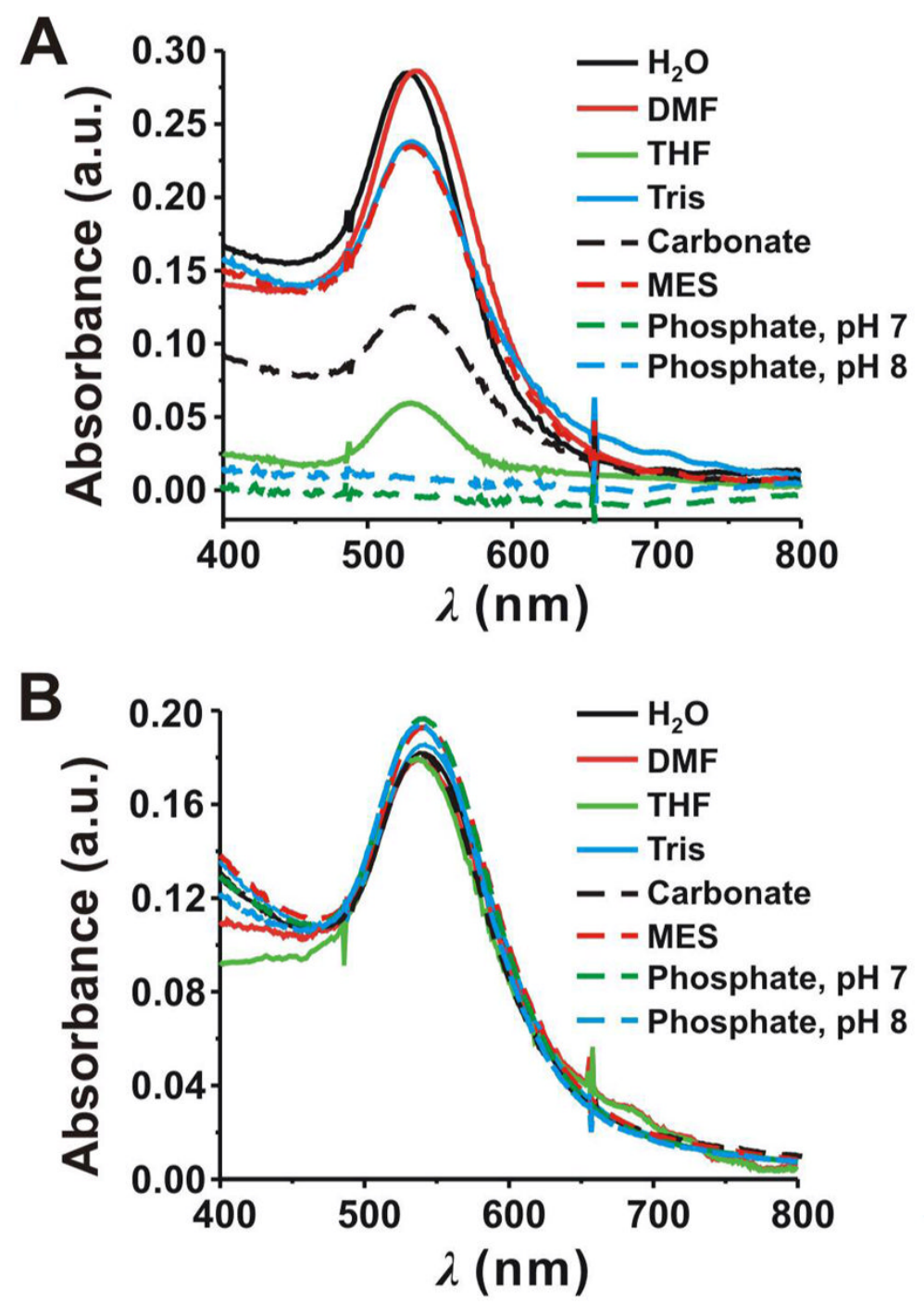

Figure 6.

UV-Vis spectra of (A) citrate-stabilized Au nanoparticles $\left(d_{\mathrm{Au}}=32.6 \mathrm{~nm}\right)$ and $(\mathrm{B})$ encapsulated Au nanoparticles $\left(d_{\mathrm{Au}}=32.6 \mathrm{~nm}, t_{\text {shell }}=11.9 \mathrm{~nm}, \mathrm{UV}\right.$-irradiated $\left.4 \mathrm{~h}\right)$ in organic solvent and pH buffers. Spectra were collected after $24 \mathrm{~h}$ in each medium. 

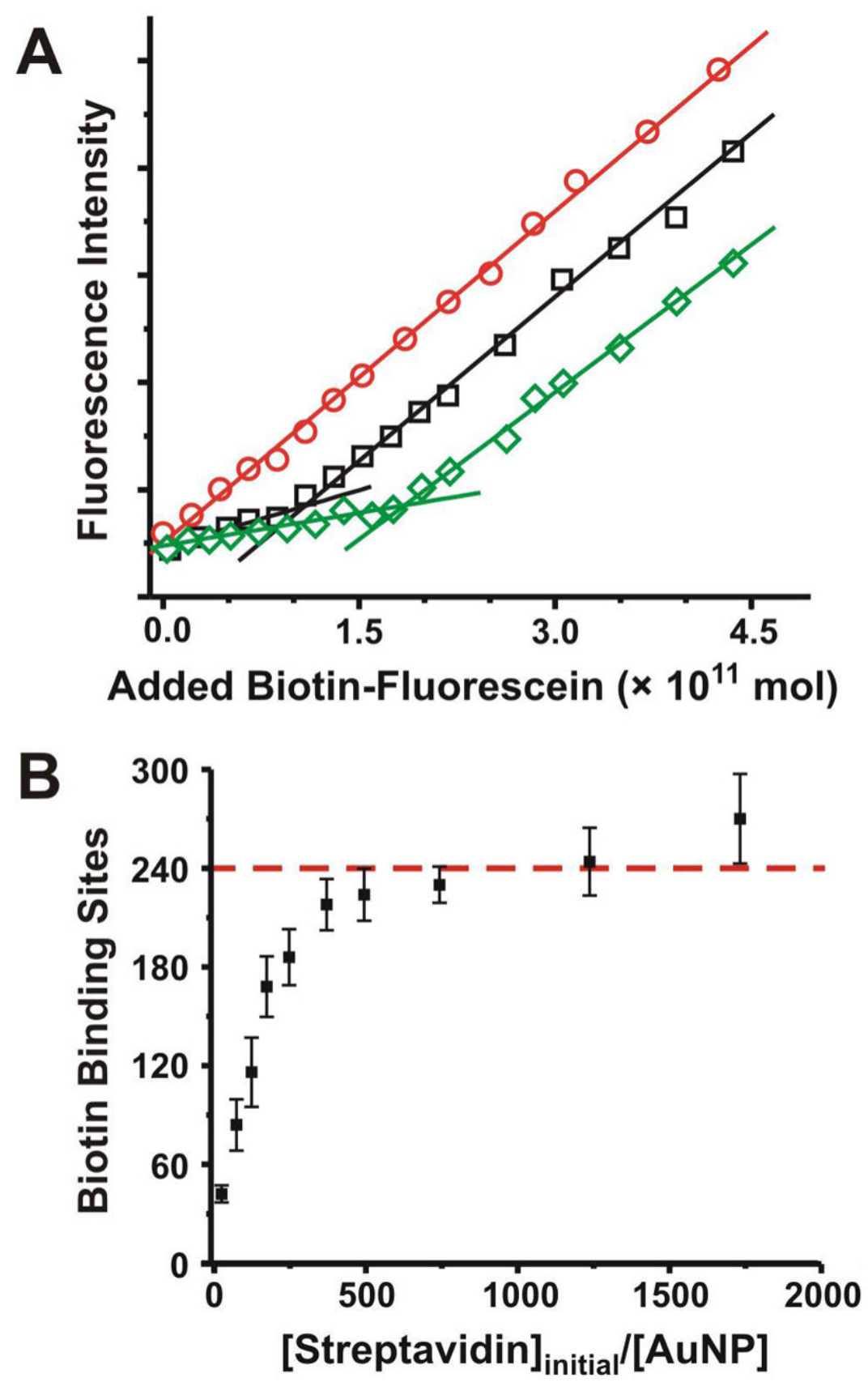

Figure 7.

(A) Plotted fluorescent intensity against added biotin-fluorescein of encapsulated $\mathrm{Au}$ nanoparticles $(\circ)$ and of streptavidin-adsorbed Au nanoparticles with initial addition of 175 $(\square)$ and 600 ( $\diamond)$ mol streptavidin/mol Au nanoparticles. For the latter two datasets, the intercept between the two linear fits represents quantitative saturation of biotin binding sites on the particles. (B) Calculated number of biotin binding sites available on each encapsulated $\mathrm{Au}$ nanoparticle for different equivalents of streptavidin added in the bioconjugation step. 